\title{
Application of Latent Class Analysis to Predict Children's Internalizing Problems
}

\author{
Young Ae Lee \\ Instructor, Department of Arts Therapy, Keimyung University, Daegu, Korea \\ 학령기 아동의 내재화문제에 대한 잠재계층 분류 및 예측요인 탐색 \\ 이영애 \\ 계명대학교 예술치료학과 강사
}

\begin{abstract}
Objectives: The purpose of this study was to identify the number of latent classes among elementary school children who internalize problems, and to find out whether internalizing problems of each latent class can be predicted by predictors.

Methods: Data were collected from 1,957 children who participated in the Korean Children and Youth Panel Survey 2010 at four different time points (grade 2, grade 3, grade 4, and grade 6). Data were analyzed using latent class analysis and multinomial logistic regression.

Results: First, analyses revealed four latent classes of children's internalizing problems: low, increasing, decreasing, and high. Second, children with high levels of self-esteem, ego-resilience, peer attachment, peer relationship, and parental monitoring are more likely to be in the low group as compared to the high group. On the other hand, children with high levels of teacher-children relationship are more likely to be in the low group as compared to the increasing group. Third, children with higher levels of abuse experiences are more likely to be in the high group than in the low group. With regards to boys and girl's internalizing problems, girls are more likely to be in the high group as compared to the low group.

Conclusion: The results suggested that internalizing problems of the extracted latent classes were differently predicted by gender, self-esteem, ego-resilience, peer attachment, peer relationship, teacher-child relationship, parental monitoring, and parental abuse.
\end{abstract}

Keywords: internalizing problems, self-esteem, parental monitoring, latent class

\section{Introduction}

학령기 아동은 아동기 이전에는 전적으로 가족의 영향 하에 놓여 있지만 학교생활이 시작되면서 가족 이외의 외부로부 터 평가, 성공과 실패의 기회, 새로 형성된 또래관계를 통해 다 양하고 복잡한 사회화 과정을 경험하게 된다. 아동의 초기 적 응 패턴은 이후의 적응에 복잡하고 상호적인 방식으로 연관될 수 있지만 힘든 조건, 적응을 위한 초기 갈등, 발달과제의 실패

Corresponding Author: Young Ae Lee, Instructor, Department of Arts Therapy, Keimyung University, Dalgubeol-daero, Dalseo-gu, Daegu 42601, Daegu, Korea

E-mail: leevivian@hanmail.net
가 반드시 부정적인 결과를 초래하는 것은 아니다. 오히려 많 은 요인들이 전환점을 제공하여서 특정 발달과제의 성취를 통 해 아동을 보다 더 적응적인 궤도로 이동하도록 한다(Mash \& Barkley, 2014). 그러나 일부 아동은 부모들의 학업성취에 대한 과도한 기대와 요구, 학업에 대한 부담과 경쟁, 또래 간 집단 따돌림 및 괴롭힘 등으로 인해 빈약한 또래관계를 형성하고, 또래집단에서 부정적 지위를 형성함으로써 소외되고 사회적 으로 위축된 행동을 나타내기도 한다. 이러한 아동의 심리사

(C)The Korean Association of Child Studies

This is an Open Access article distributed under the terms of the Creative Commons Attribution Non-Commercial License (http:// creativecommons.org/licenses/by-nc/4.0) which permits unrestricted noncommercial use, distribution, and reproduction in any medium, provided the original work is properly cited. 
회적 부적응 및 문제행동은 크게 내재화와 외현화 문제로 범 주화된다(Keily, Bates, Dodge, \& Pettit, 2000). 이 중 내재화 문 제는 소극적이고 과잉 통제된 행동의 문제로 우울, 불안, 사회 적 위축, 신체증상 등이 포함된다. 아동의 내재화 문제는 인지 기능(Bub, McCartney, \& Willett, 2007)의 저하, 또래관계 등 사 회적 관계의 어려움을 야기하고(Hoglund \& Chisholm, 2014), 아동기와 그 이후 시기까지 만성적으로 지속되는 경향이 있다 (O’Connor, Dearing, \& Collins, 2011). 따라서 아동기의 건강한 적응과 발달은 이후의 삶에 대한 토대가 된다는 점에서 발달 과제의 성취를 통해 유능성을 촉진하고 부적응을 겪지 않도록 사전에 예방하는 것이 중요하다. 이를 위해서는 학령기에 있 는 아동의 발달 과정에서 내재화 문제의 발생과 유지, 증가 및 감소 등의 변화와 안정성은 어떠한 형태를 나타내며 이에 관 계되는 예측요인에 대해 탐색해볼 필요가 있다.

아동 및 청소년기 내재화 문제에 대한 선행연구들은 몇 가 지 경향으로 나누어 살펴볼 수 있다. 먼저, 특정 시기나 연령에 서 자아존중감과 사회적 지지(Song \& Shin, 2014), 부모양육행 동( Jo \& Kim, 2014; Nam, Sung, \& Gwon, 2014), 또래관계의 문제(Hoglund \& Chisholm, 2014) 등 단일의 요인들이 내재화 문제를 유의미하게 예측하는지를 규명하거나 특정 변인과의 관련성 및 구조적 관계를 밝힌 변수 중심의 연구들이 다양하 게 수행되었다. 이러한 연구들은 아동의 내재화 문제에 관계 되는 변인들 간의 관련성을 밝히고 있으나 학령기 아동의 중 요한 환경적 맥락인 또래, 학교, 가족 및 부모의 다중요인을 고 려하지 못한 제한점이 있다.

다음, 국 - 내외에서 패널조사에 의한 종단자료를 활용하 여 아동과 청소년기의 발달단계에서 시간의 흐름에 따른 내재 화 문제의 변화양상 및 예측요인을 탐색하는 연구를 통해 내 재화 문제는 전반적으로 증가하는 것으로 밝히고 있다(Jwa \& Byeon, 2010; Kang, 2014; E.-J. Lee, 2010; J.-R. Lee, 2008; Wang, Williams, Shahaeian, \& Harrison, 2018). 또 다른 연구경향으로 연령에 따른 내재화 문제의 개인 간 변화양상을 잠재집단으 로 분류하여 유형화하고 예측요인을 규명하는 연구가 이루어 졌다. 3세 15 세 아동과 청소년(Davis, Votruba-Drzel, \& Silk, 2015; Sterba, Prinstein, \& Cox, 2007)의 내재화 문제에 대한 발 달궤적은 3 개에서 6 개의 하위집단으로 구분되었다. 잠재계층 분석 방법을 적용하여 중국 빈곤지역 아동의 내재화와 외현화 문제는 3 개(Herman, Bi, Borden, \& Reinke, 2012), 정신건강 서 비스에 의뢰된 11 세에서 18 세 청소년의 불안은 3 개, 우울은 4 개의 잠재계층으로 분류되었다(Ferdinard, de Nijs, van Lier, \& Verhulst, 2005). 한편, 국내의 선행연구에서는 초등학교 4학
년부터 중학교 1학년 아동과 청소년을 대상으로 우울(No \& Hong, 2010), 초등학생 남녀 아동을 대상으로 교사평가에 의 한 내재화와 외현화 문제행동(Gang, Kim, Yun, \& Lim, 2012) 에 대한 잠재계층은 각각 4 개로 분류되었다. 그리고 중. 고등 학생을 대상으로 우울, 불안, 공격성의 문제행동에 대한 잠재 계층은 4개로 분류되었다(Choi, 2010). 이들 연구는 사람중심 접근방법(person-centered approach)을 적용하여 연구 대상이 가질 수 있는 특수성에 초점을 두어 모집단 내에서 이질적인 특성을 보이는 잠재계층을 분류하여 아동 및 청소년기 내재화 문제의 발달에 대한 이해의 폭을 확장하였다. 이러한 선행연 구는 대부분 초등학교 4학년에서 중학교 2학년, 중학생과 고 등학생 등 특정한 발달단계 혹은 연령에 해당되는 아동과 청 소년을 대상으로 이루어져, 초등학교 저학년과 고학년의 학령 기 아동에 대한 연구는 충분치 않다. 이러한 점을 보완하기 위 해 전국에서 표집 된 아동을 대상으로 한 패널조사 자료를 사 용하여 학령기 아동의 내재화 문제에 대한 잠재계층은 어떠한 형태를 나타내는지 알아볼 필요성이 제기된다.

한편, 발달정신병리 관점, 교류적 관점 그리고 생태학적 관점에 의하면 아동의 발달과정에서 적응적 발달, 부적응적 문제행동 및 정신병리적 증상은 아동을 둘러싼 다양한 사회 적·환경적 맥락 간의 상호적인 교류를 통해 영향을 주고받는 다는 것이다(Mash \& Barkley, 2014). 다시 말하자면, 아동 및 청 소년의 성장과 발달에서 경험하는 문제 또한 그들이 생활하 는 사회적·문화적 맥락과 밀접한 관련이 있다는 점을 강조하 는 것으로 아동은 가족, 또래, 학교, 이웃, 사회적 · 문화적 상황 을 포함하는 환경적 맥락의 틀 안에서 생활하기 때문이다. 이 렇듯 아동의 심리적 문제를 의미 있게 분석하기 위해서는 개 인을 발달적 맥락을 고려할 필요가 있다는 측면에서 내재화 문제의 발달은 복잡하고 개인적 특성, 또래, 학교, 가족 등의 환경적 맥락과 시간과의 결합에 의해 촉발되는 것으로 볼 수 있다(Bronfenbrenner \& Morris, 2006). 내재화 문제의 발달에 관계되는 요인은 다양하지만 Keily, Lofthouse, Bates, Dodge와 Pettit (2003)의 연구에서 5세에서 14 세까지의 아동을 대상으 로 내재화 문제를 예측하는 개인적 특성, 사회문화적 요인, 부 모양육요인, 또래요인에 대한 탐색을 통해 내재화 문제의 유 지, 증가, 감소에 작용하는 고유요인과 공통요인을 밝히고 있 다. 앞서 살펴본 이론적 관점과 선행연구를 토대로 내재화 문 제의 발달에 관계되는 아동기의 중요한 환경적 맥락인 또래 및 학교요인, 부모요인, 그리고 개인적 요인을 중심으로 관련 선행연구를 살펴보고자 한다.

먼저, 학령기 아동은 학년이 높아질수록 학교에서 보내는 
시간이 많아지기 때문에 또래 및 교사를 포함하는 학교환경 은 아동의 성장과 발달에 중요하다(S. Lee, 2008). 학령기 아 동의 또래관계의 형성과 유지에 직접 혹은 간접적으로 작용 하는 또래애착은 또래와의 친밀한 유대관계를 유지할 수 있 다는 아동 자신의 믿음을 의미한다. 이러한 또래애착은 11 세 에서 19세 청소년의 내재화 문제에 대한 예측요인으로 아동 과 청소년에게 정서적 지지를 제공하여(Choi, 2010; Tambelli, Laghi, Odorisio, \& Notari, 2012) 우울 등의 내재화 문제의 발 달 가능성을 낮추는 보호적 기능을 하는 것으로 제시하고 있 다(Bukowski, Laursen, \& Hoza, 2010; Duchene \& Ratelle, 2014; Jang \& Chung, 2019). Millings, Buck, Montgomery, Spears와 Stallard (2012)의 연구에서 11세에서 16세 청소년의 우울은 또 래애착, 자아존중감, 학교 소속감과 관계가 있으며, 또래애착 과 자아존중감은 학교 소속감보다 낮은 우울을 더 크게 예측 하는 것으로 제시하였다. 또, 5 세에서 14 세 아동의 또래거부 와 무시는 내재화 문제에 대한 위험요인으로 확인되었으며 (Keily et al., 2003), 학령기 아동의 내재화 문제는 교사와의 애 착(Koo, 2004) 및 학교적응과의 관계에서 매개효과를 나타내 었다(H.-E. Lee \& Moon, 2011). 이들 선행연구는 대부분 내재 화 문제에 대한 또래, 학교와 관련된 단일의 변인에 대한 구조 적 관계를 분석한 것으로 학령기 아동의 중요한 환경적 맥락 인 또래 및 학교요인에 대한 구체적인 정보를 제시하지 못하 는 제한점이 있다.

다음, 아동의 문제행동의 야기에는 또래, 교사, 학교 등 여 러 환경적 맥락에 관련된 요인이 작용하지만 사회화의 1 차적 담당체인 가정 및 가족환경의 적절치 못한 기능 수행의 결과 로 이해될 수 있다. 아동의 내재화 문제를 예측하는 부모, 가족 및 가정환경 요인으로 부모의 양육행동, 부모-자녀 관계, 부 모애착, 부부갈등, 부모의 행동통제 및 가족의 사회경제적 지 위 등에 관한 연구가 수행되었다(Davis et al., 2015; Jwa, 2016; Keily et al., 2003). 부모양육행동의 한 형태인 부모의 지도감 독 부재, 학대 등 처벌적, 강압적인 양육행동은 높은 수준의 우 울 및 내재화 문제를 야기하는 것으로 제시되었다(Jwa, 2010; J.-R. Lee, 2008). 또, 부모의 양육행동과 아동의 또래관계와의 관련성에 있어 부모의 애정과 수용, 정서적 상호작용 및 모 애 착은 아동이 타인의 감정에 대한 관심을 발달시키고, 거부적 이고 처벌적인 양육행동은 아동의 적대적이고 공격적인 행 동, 낮은 또래 수용과 유의미한 관계가 있는 것으로 나타났다 (Davis et al., 2015). 본 연구에서는 부모 및 가족과 관련된 환경 적 변인 중 부모의 양육행동이 아동의 또래문제 및 내재화 문 제와의 관련성을 밝힌 선행연구에 근거하여 부모의 온정, 지
도감독, 학대를 부모요인의 예측변인으로 선정하였다.

또한, 내재화 문제에 대한 예측요인은 또래, 학교, 가족 등 의 환경적 맥락과 함께 아동의 개인내적인 특성 또한 고려되 어야 할 요소이다. 아동의 내재화 문제에 관련되는 개인적 특 성으로 기질, 자아존중감, 정서조절, 자아탄력성, 자기통제 력, 스트레스 및 부정적 정서성을 들 수 있다(Davis et al., 2015; Jwa, 2016). 이 중 자아존중감은 개인이 자신에 대하여 지각하 는 태도에서 나타나는 자신에 대한 가치 판단이다. 그리고 자 아탄력성(ego-resilience)을 상황적 요구나 스트레스가 많은 환 경에서 성공적인 적응을 위해 개인의 자아통제수준을 강화 또는 완화시키는 능력으로 적응에 중요한 요소라고 할 수 있 다. 자아존중감은 또래관계의 수준, 또래지위에 따라 차이가 있고(Bolger, Patterson, \& Kupersmidt, 1998), 학업적 및 사회적 자아존중감은 또래관계를 예측하는 것으로 나타났다(Cho \& Lee, 2007; Han \& Moon, 2011). 그리고 자아존중감의 향상은 1 년 후의 내재화 문제를 조절하는 것으로 밝히고 있다(Kim \& Cicchetti, 2004; Song \& Shin, 2014). 또한, 아동의 자아탄력성 은 어머니의 애정적 양육행동과 정적 관계가 있으며(Shonk \& Cicchetti, 2001), 내재화 문제에 대한 여러 보호요인 중의 하나 에 해당하였다(Jwa, 2016). 다시 말해, 탄력성이 높은 아동은 위기나 어려운 상황에서 사회적 유능감과 적응적 기능으로 대 처하고, 청소년기와 성인기에 정신병리를 나타날 가능성이 낮 으며 낮은 수준의 심리사회적 적응 혹은 내재화 문제를 나타 내는 것으로 입증되었다. 이와 같이 자아탄력성, 자아존중감 은 아동에게 의미 있는 타자인 부모, 또래, 교사의 평가 및 피 드백을 통해 촉진되기도 하고 저하될 수 있음을 알 수 있다. 따 라서 자아존중감과 자아탄력성은 아동 및 청소년의 적응적 발 달에 보호 혹은 위험요인으로 작용할 가능성을 제시하기 때문 에 내재화 문제에 관계되는 개인 요인으로 선정하였다. 내재 화 문제에 관련되는 개인 요인 중 성별 차이에 관한 연구를 살 펴보면, 초등학교 4학년에서 중학생 혹은 고등학생 시기에 걸 쳐 내재화 문제 및 우울(Jo \& Kim, 2014; Kang, 2014), 5세에서 17세(Keily et al., 2003; Leve, Kim, \& Pears, 2005), 10세에서 13 세(Lee \& Stone, 2012)의 아동과 청소년의 내재화 문제 수준은 여자가 남자에 비해 증가하는 것으로 나타남으로써 성별 차이 를 확인하였다. 그리고 Sterba 등(2007)의 연구에서 2세에서 11 세 아동의 내재화 문제는 전체적으로 여자는 남자보다 증가하 는 집단에 포함되었으나 높은 집단 및 감소/증가하는 집단은 낮은 집단 간 성별 차이는 작은 것으로 나타나 대상자의 연령, 잠재집단의 유형에 따라 일관되지 않은 측면이 제시되었다.

따라서 본 연구 목적은 한국아동 - 청소년 패널조사 자료를 


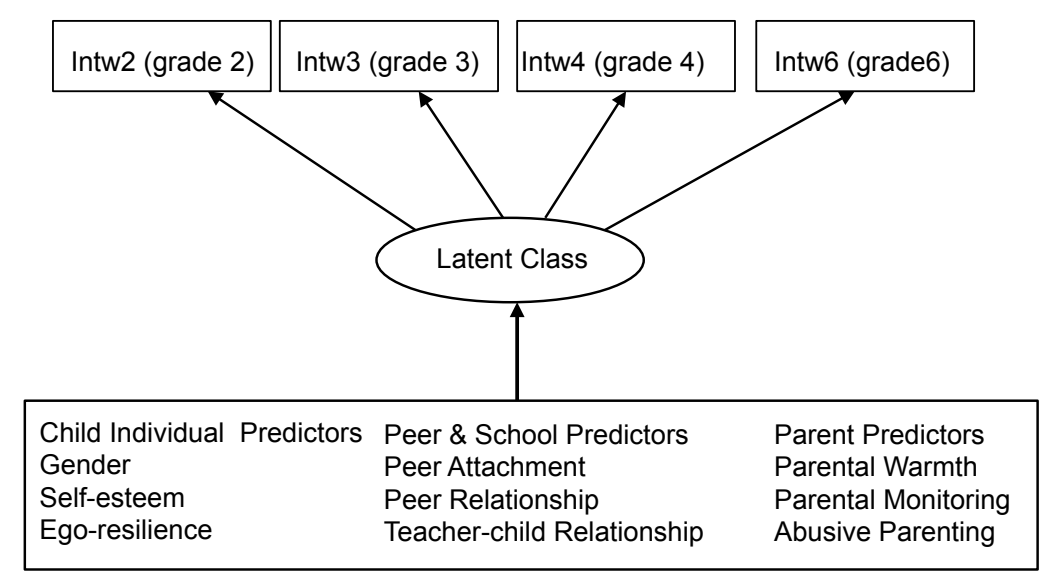

Figure 1. Conceptual model of latent class analysis of internalizing problems and predictors. Intw2, Intw3, Intw4, Intw5 = internalizing problems at waves 2 (grade 2), 3 (grade 3), 4 (grade 4), and 6 (grade 6).

활용하여 잠재계층분석 (latent class analysis) 방법을 적용하여 학령기 아동의 내재화 문제에 대한 잠재계층을 분석하여 그 유형을 파악하는 것이다. 또, 개인 요인(성별, 자아존중감, 자 아탄력성), 또래 및 학교요인(또래애착, 또래관계, 교사관계), 부모요인(부모의 지도감독, 애정, 학대)은 잠재계층별 내재화 문제를 예측하는지를 알아보고자 한다. 이를 통해 학령기 아 동의 내재화 문제에 대한 잠재계층 별 차이와 특징을 살펴볼 수 있다. 그리고 잠재계층에 따른 내재화 문제를 예측하는 요 인을 파악함으로써 학령기 아동의 내재화 문제행동의 발생을 예방하기 위한 개입방법을 모색하는데 필요한 기초자료를 제 공할 수 있을 것이다. 이에 따른 연구모형은 그림 1 에 제시하 였고 연구문제는 다음과 같이 설정하였다.

\section{연구문제1}

학령기 아동의 내재화 문제는 몇 개의 잠재계층으로 분류되는가?

\section{연구문제2}

개인요인(성별, 자아존중감, 자아탄력성), 또래 및 학교요인 (또래애착, 또래관계, 교사관계), 부모요인(부모감독, 애정, 학대)은 잠재계층별 내재화 문제를 예측하는가?

\section{Methods}

\section{연구대상}

연구문제를 검증하기 위해 한국아동 - 청소년패널조사(Korean Children and Youth Panel Survey [KCYPS], 2016)의 초1 패널자료
를 활용하였다. 초1 패널조사는 한국청소년정책연구원이 전국 의 초등학교 1학년 아동 2,342명과 그 부모를 대상으로 2010년 부터 2017년 까지 7년 동안 반복적으로 조사를 수행하였다. 본 연구에서는 2011년부터 2016년까지 조사된 2차, 3차, 4차와 6차 년도의 4 개년 자료를 사용하였으며, 내재화 문제에 대한 조사 가 이루어지지 않은 1 차 년도와 5 차 년도는 제외되었다. 초1 패 널조사의 대상자는 전국에서 표집 된 2,342명이었으나 내재화 문제에 관한 문항에 반응하지 않은 사례를 제외한 1,957 명(남 자: 1,006 명, 여자: 951 명)이다. 이들 대상자는 초등학교 2학년(2 차), 3학년(3차), 4학년(4차), 그리고 6학년(6차)에 해당한다.

\section{연구변인 및 척도}

\section{내재화 문제}

내재화 문제는 초 1 패널 조사 자료 중 신체증상 8 문항, 사회적 위축 5 문항, 우울 8 문항이 포함된 23 문항으로 측정되었다. 문 항 내용은 “자주 머리가 아프다.”, “주위에 사람이 많으면 어색 하다.", "어떤 일이 잘못되었을 때 자신 때문이라는 말을 자주 한다.” 등으로 구성되어 있다. 점수가 높을수록 내재화 문제 수준이 높은 것을 의미한다. 2 차와 3 차의 내재화 문제는 부모 에 의해 평가되었고 4차와 6차는 아동의 자기평가로 측정되 었다. 신뢰도(Cronbach's $\alpha$ )는 2차년도 .903, 3차년도 .917, 4차 년도. 924,6 차 년도는 .933 이다.

$$
\text { 예측요인 }
$$

자아존중감 척도는 10 문항으로, 문항의 구성은 "나는 내가 하 
고자 하는 일을 적어도 남들만큼은 할 수 있다.” 등으로 되어 있다. 자아탄력성 척도는 14 문항으로, 문항의 구성은 "나는 다른 사람들보다 호기심이 많다.", "내가 만나는 대부분의 사 람들이 좋다.” 등으로 되어 있다. 자아존중감과 자아탄력성 의 신뢰도는 각각 .825 과 .899이다. 또래애착 척도는 소외, 의 사소통, 신뢰의 하위영역 각 3 문항씩 총 9문항으로, 또래관계 를 잘 맺고 유지하고 있다고 스스로 지각하는 정도를 의미한 다. 신뢰도는 .804이다. 교우관계는 "우리 반 아이들과 잘 어울 린다.” 등, 교사관계는 “학교 밖에서 선생님을 만나면 반갑다.” 등으로 각각 5 문항으로 되어 있고 점수가 높을수록 또래관계 및 교사관계의 수준이 높음을 나타낸다. 신뢰도는 각각 .658 과 .861이다. 부모 감독의 척도는 "내가 시간을 어떻게 보내는 지 알고 계신다.” 등의 3 문항, 부모의 애정에 관한 척도는 "나 에게 칭찬을 잘 해주신다.” 등의 4문항으로 구성되어 있으며 신뢰도는 각각 . 706 과 .838이다. 학대 척도는 4문항으로, 부모 가 의도적으로 자녀에게 해를 주고 신체적인 손상이라는 결과 가 남는 행위로, 점수가 높을수록 부모가 자녀를 처벌적으로 대하는 양육행동을 의미한다. 신뢰도는 .826이다. 앞서 제시한 모든 변수들의 척도는 4점 리커트 척도로 평정하였고, 일부 척 도의 문항은 분석과 해석상의 편이를 위해 역환산하였으며 성 별은 여자(0), 남자(1)로 변환하였다.

\section{연구 절차 및 분석 방법}

첫째, 본 연구에서 선정한 변수들의 신뢰도(Cronbach's $\alpha$ ), 평 균, 표준편차, 왜도, 첨도 및 상관계수를 확인하였다. 둘째, 학 령기 아동의 내재화 문제에 대한 잠재계층을 알아보기 위해 잠재계층을 수행하였다. 이를 통해 분류된 집단은 추정을 통 해 나타나는 집단이므로 잠재계층(latent class)라고 할 수 있으 며, 본 연구에서는 잠재집단과 잠재계층이라는 용어를 혼용하 여 사용하였다. 잠재계층분석을 통해 잠재계층의 수를 결정하 기 위해서 AIC, BIC, Adjusted BIC, Entropy, LMR-LRT, BLRT 등의 지수를 종합적으로 고려하였다. AIC와 BIC 및 Adjusted $\mathrm{BIC}$ 는 표집의 크기, 최종 모수의 수를 고려하여 모형 적합지 수의 값들이 낮을수록 좋은 모형으로 판단한다. 다음, LMRLRT, BLRT 검증은 잠재계층의 수가 $k-1$ 개인 모형과 $k$ 개인 모 형의 유의확률에 의해 잠재계층의 수를 정한다. Entropy는 개 별의 사례가 주어진 계층에 얼마나 잘 분류되는지를 보여주는 모형 적합지수로 0 에서 1 까지의 값을 가지고 0.8 이상이면 분 류의 질이 양호한 것으로 판단한다(Jung \& Wickrama, 2008). 그리고 분류된 잠재계층 별 특징에 따라 명명하고 각 집단의
내재화 문제에 대한 평균을 산출하여 그래프로 제시하였다. 넷째, 다항로지스틱 회귀분석을 통해 잠재계층 별 내재화 문 제에 대한 예측요인 각각의 추정치(Estimate)를 확인하여 비교 하였다. 분석에는 Mplus 7.4 (Muthén \& Muthén, 1998-2002)와 SPSS 21.0 (IBM Co., Armonk, NY)을 사용하였다.

\section{Results}

\section{변수들의 기술통계 및 상관}

연구문제를 검증하기 위해 선정된 모든 변수들의 기술 통계 치, 왜도, 첨도 및 상관계수를 산출한 결과는 Table 1과 같다. 모든 변수들은 왜도의 절대 값이 2 미만, 첨도의 절대 값이 4 미만이었다. 내재화 문제의 평균은 2 차와 3 차에 비해 4 차와 6 차에서 높았다. 주요 변수들 간 상관은 내재화 문제 2 차와 3 차, 4 차와 6 차간에는 정적으로 유의한 상관을 나타내었다( $r s$ $=.57 \sim .13, p<.01)$. 내재화 문제와 자존감 $(r s=-.07 \sim .40, p$ $<.01)$, 자아탄력성 $(r s=-.09 \sim .23, p<.01)$, 또래애착 $(r s=-.05$ $\sim .33, p<.01)$, 교우관계( $r s=-.05 \sim .43, p<.01)$, 교사관계( $r s=$ $-.04 \sim .32, p<.01)$, 부모감독 $(r s=-.09 \sim .23, p<.01)$ 간 에는 부 적 상관이 통계적으로 유의하였다.

\section{내재화 문제에 대한 잠재계층 분류}

학령기 아동의 내재화 문제에 대한 잠재계층을 분류하기 위 해 잠재계층분석을 적용하였다. 적합한 잠재계층의 수를 결정 하기 위해 2 개부터 시작하여 5 개까지 잠재계층의 수를 증가 시키면서 모형 적합지수를 비교하였다. 잠재계층의 수에 따른 모형 적합지수의 값은 Table 2 와 같다. 이를 살펴보면, 잠재계 층의 수가 많아질수록 $\mathrm{AIC}, \mathrm{BIC}$ 및 $\mathrm{ABIC}$ 값의 크기는 계속 낮 아지고, 분류의 정확도를 나타내는 Entropy 값은 5개 계층 모 형일 때 가장 높게 나타났으며, BLRT는 5개 계층 모형까지 통 계적으로 유의하게 나타났다. 그러나 계층 5 모형은 전체 표본 대비 비율이 $5 \%$ 미만인 계층이 포함되어 있고, LMR-LRT에 서 4계층 모형과 5계층 모형 간 차이가 통계적으로 유의하지 않았다 $(p=.096)$. 따라서 최종 잠재계층 수는 모형 적합지수 와 해석가능성을 종합적으로 고려하여 4 개의 잠재계층이 가 장 적합한 모형이라고 판단하였다.

학령기 아동의 학년 별 내재화 문제에 대해 4 개로 분류된 잠재계층 별 평균과 표준편차는 Table 3 과 같다. 학년과 잠재 
Table 1

Means, Standard Deviations, and Correlation Among Variables

\begin{tabular}{|c|c|c|c|c|c|c|c|c|c|c|c|c|c|}
\hline & 1 & 2 & 3 & 4 & 5 & 6 & 7 & 8 & 9 & 10 & 11 & 12 & 13 \\
\hline 1 & - & & & & & & & & & & & & \\
\hline 2 & $.57^{* *}$ & - & & & & & & & & & & & \\
\hline 3 & $.13^{* *}$ & $.16^{* *}$ & - & & & & & & & & & & \\
\hline 4 & $.15^{* *}$ & $.18^{* *}$ & $.44^{* *}$ & - & & & & & & & & & \\
\hline 5 & -.03 & $-.06^{* *}$ & .02 & $-.09^{* *}$ & - & & & & & & & & \\
\hline 6 & $-.07^{* *}$ & $-.13^{* *}$ & $-.41^{* *}$ & $-.40^{* *}$ & $.05^{*}$ & - & & & & & & & \\
\hline 7 & $-.09^{* *}$ & $-.14^{* *}$ & $-.35^{* *}$ & $-.23^{* *}$ & $-.05^{*}$ & $.33^{* *}$ & - & & & & & & \\
\hline 8 & $-.05^{*}$ & $-.11^{* *}$ & $-.34^{* *}$ & $-.33^{* *}$ & $-.12^{* *}$ & $.49^{* *}$ & $.27^{* *}$ & - & & & & & \\
\hline 9 & $-.05^{*}$ & $-.09^{* *}$ & $-.43^{* *}$ & $-.20^{* *}$ & $-.15^{* *}$ & $.34^{* *}$ & $.51^{* *}$ & $.40^{* *}$ & - & & & & \\
\hline 10 & -.04 & $-.08^{* *}$ & $-.32^{* *}$ & $-.14^{* *}$ & $-.16^{* *}$ & $.26^{* *}$ & $.41^{* *}$ & $.23^{* *}$ & $.52^{* *}$ & - & & & \\
\hline 11 & $-.05^{*}$ & $-.06^{* *}$ & $-.28^{* *}$ & $-.13^{* *}$ & $-.13^{* *}$ & $.23^{* *}$ & $.36^{* *}$ & $.27^{* *}$ & $.40^{* *}$ & $.34^{* *}$ & - & & \\
\hline 12 & $-.05^{*}$ & $-.10^{* *}$ & $-.38^{* *}$ & $-.20^{* *}$ & $-.06^{*}$ & $.35^{* *}$ & $.45^{* *}$ & $.30^{* *}$ & $.50^{* *}$ & $.45^{* *}$ & $.51^{* *}$ & - & \\
\hline 13 & $.05^{*}$ & $.05^{*}$ & $.29^{* *}$ & $.17^{* *}$ & $.17^{* *}$ & $-.25^{* *}$ & $-.14^{* *}$ & $-.20^{* *}$ & $-.24^{* *}$ & $-.16^{* *}$ & $-.14^{* *}$ & $-.33^{* *}$ & - \\
\hline $\bar{N}$ & 1957 & 1957 & 1957 & 1957 & 1957 & 1935 & 1957 & 1935 & 1957 & 1957 & 1957 & 1957 & 1957 \\
\hline$M$ & 36.75 & 36.84 & 37.63 & 41.41 & .51 & 32.86 & 41.93 & 28.53 & 16.29 & 16.31 & 10.43 & 13.41 & 6.66 \\
\hline$S D$ & 8.42 & 8.78 & 11.15 & 12.24 & .50 & 4.59 & 7.81 & 4.40 & 2.37 & 3.16 & 1.72 & 2.39 & 2.68 \\
\hline Sk & .39 & .28 & .80 & .48 & -.06 & -.35 & -.38 & -.39 & -.26 & -.77 & -1.19 & -.87 & 1.43 \\
\hline $\mathrm{Ku}$ & -.51 & -.79 & .48 & -.21 & -2.00 & -.34 & .27 & .25 & -.41 & .46 & 1.46 & .66 & 2.07 \\
\hline
\end{tabular}

Note. 1 = internalizing problem wave 2; 2 = internalizing problem wave 3; 3 = internalizing problem wave 4; $4=$ internalizing problem wave 6; 5 = Gender; 6 = self-esteem; 7 = ego-resilience; 8 = peer attachment; 9 = peer relationship; $10=$ teacher-child relationship; $11=$ parental monitoring; 12 = parental warmth; 13 = abusive parenting; Sk = skewness; Ku = kurtosis.

${ }^{*} p<.05 .{ }^{* *} p<.01 .{ }^{* * *} p<.001$.

Table 2

Model Selection and Model Fit Indices of Latent Class Analysis

\begin{tabular}{|c|c|c|c|c|c|}
\hline & & \multicolumn{2}{|c|}{ Latent classes } & \multirow[b]{2}{*}{ 4-class model } & \multirow[b]{2}{*}{ 5-class model } \\
\hline & & 2-class model & 3-class model & & \\
\hline$\overline{\mathrm{AIC}}$ & & 57409.942 & 57158.098 & 56874.003 & 56786.818 \\
\hline $\mathrm{BIC}$ & & 57482.471 & 57258.523 & 57002.324 & 56943.035 \\
\hline $\mathrm{ABIC}$ & & 57441.170 & 57201.337 & 56929.252 & 56854.078 \\
\hline LMR-LRT $p$-value & & 0.000 & 0.019 & 0.000 & 0.096 \\
\hline BLRT $p$-value & & 0.000 & 0.000 & 0.000 & 0.000 \\
\hline Entropy & & 0.719 & 0.703 & 0.738 & 0.764 \\
\hline \multirow[t]{5}{*}{ Class counts and proportions } & Class 1 & $1105(56.46 \%)$ & $1038(53.04 \%)$ & $792(40.47 \%)$ & $748(38.22 \%)$ \\
\hline & Class 2 & $852(43.53 \%)$ & $260(13.28 \%)$ & $312(15.94 \%)$ & $359(18.34 \%)$ \\
\hline & Class 3 & & $659(33.67 \%)$ & $164(8.38 \%)$ & $550(28.10 \%)$ \\
\hline & Class 4 & & & $689(35.20 \%)$ & $260(13.28 \%)$ \\
\hline & Class 5 & & & & $40(2.04 \%)$ \\
\hline
\end{tabular}

Note. Models with the best fit are shown in bold; AIC = akaike information criteria; BIC = bayesian information criteria; ABIC = samplesize adjusted BIC; LMR-LRT $p$-value = Lo, Mendell, and Rubin likelihood ratio test; BLRT $p$-value = parametric bootstrapped likelihood ratio test.

계층 별 평균 점수는 차이가 있는 것으로 나타났다. 4개의 잠 재계층 별 내재화 문제의 평균 점수의 높고 낮은 특징에 따라 명명하여 Figure 1의 그래프에 제시하였다.

잠재계층 1 은 내재화 문제의 평균보다 낮은 유형으로 저수
준 집단으로 조사자 대상자 1,957 명 가운데 792 명(40.47\%)으 로 분류되었고, 잠재계층 2 는 내재화 문제의 평균이 2차(초2), 3차(초3) 보다는 4차(초4)와 6차(초6)에서 현저히 증가하여 증 가 집단으로 명명하였으며, 312명(15.94\%)이 포함되었다. 잠 
Table 3

Means, Standard Deviation for Internalizing Problems by Latent Classes

\begin{tabular}{|c|c|c|c|c|c|c|c|c|}
\hline & \multicolumn{2}{|c|}{$\begin{array}{c}\text { Class } 1 \\
\text { (Low) }\end{array}$} & \multicolumn{2}{|c|}{$\begin{array}{c}\text { Classs } 2 \\
\text { (Increasing) }\end{array}$} & \multicolumn{2}{|c|}{$\begin{array}{l}\text { Class } 3 \\
\text { (High) }\end{array}$} & \multicolumn{2}{|c|}{$\begin{array}{c}\text { Class } 4 \\
\text { (Decreasing) }\end{array}$} \\
\hline & $M$ & $S D$ & $M$ & $S D$ & $M$ & $S D$ & $M$ & $S D$ \\
\hline Intw3 & 29.62 & 4.40 & 33.12 & 4.40 & 48.93 & 5.35 & 43.95 & 5.07 \\
\hline Intw4 & 31.66 & 6.63 & 51.36 & 6.63 & 54.17 & 8.99 & 34.34 & 7.56 \\
\hline
\end{tabular}

Note. $N=1,957$; Intw2, Intw3, Intw4, Intw5 = internalizing problems at Waves 2 (grade 2), 3 (grade 3), 4 (grade 4), and 6 (grade 6).

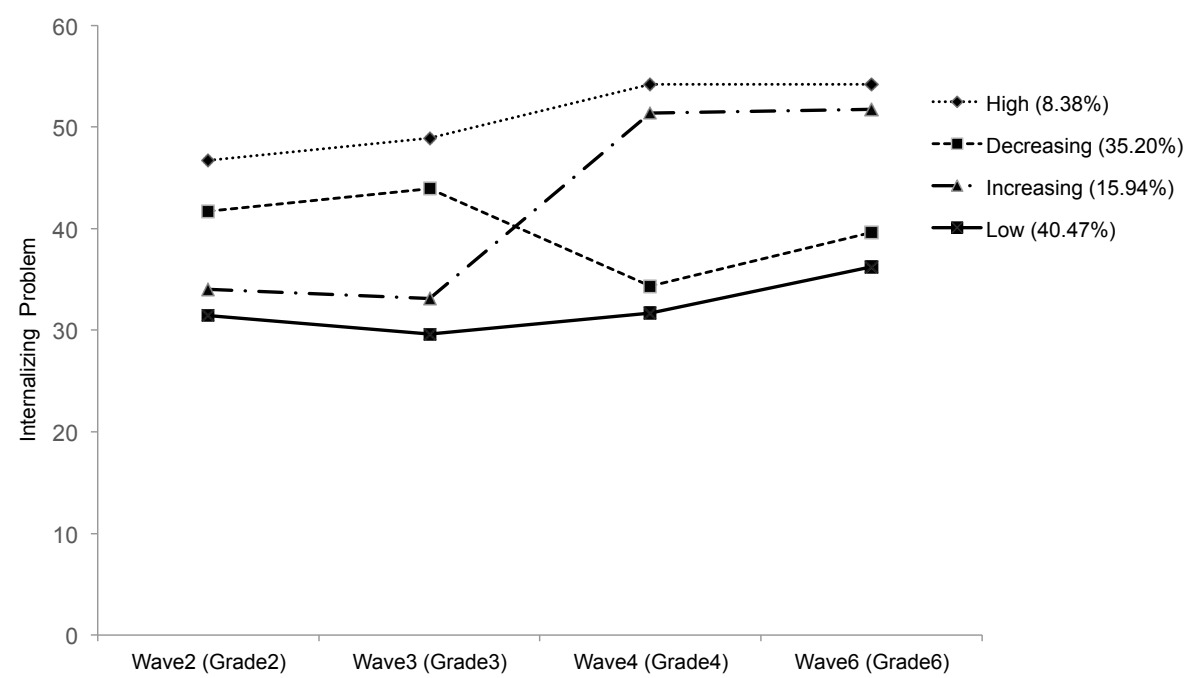

Figure 2. Characteristics of latent classes on internalizing problems.

재계층 3은 내재화 문제의 평균보다 높아 고수준 집단으로, 164 명 $(8.38 \%)$ 으로 분류되었다. 잠재계층 4 는 내재화 문제의 평균이 2,3 차 보다는 4 차와 6 차에서 감소하여 감소 집단으로 명명하였으며, 689명(35.20\%)이 포함되었다.

\section{잠재계층 별 내재화문제에 대한 예측요인}

잠재계층 별 내재화 문제에 대한 예측변인의 추정치(estimate) 를 알아보기 위한 다항로지스틱 회귀분석 결과는 Table 4와 같 다. 각각의 예측요인에 대한 추정치는 준거집단과 비교하여 나머지 3 개 집단 중의 하나에 속할 확률을 나타낸다. 잠재계층 간 비교를 위해 저수준형을 준거집단으로 선정하였다. 준거집 단과 3 개 집단 별 예측변인의 추정치를 고수준 집단과 저수준 집단을 비교하여 살펴보았다. 개인요인에서 성별의 경우 여학 생일수록 $(b=-1.206, p<.001)$ 저수준집단 보다 고수준 집단에 포함될 가능성이 높았다. 그리고 자아존중감, 자아탄력성이
높을수록 고수준 집단보다 저수준 집단에 속할 가능성이 더 높았다 $(b=-0.211, p<.001, b=-0.082, p<.001)$. 다음, 또래 및 학교요인에서 또래애착, 교우관계 수준이 높을수록 저수준 집 단에 속할 가능성이 더 높았다 $(b=-0.084, p<.05, b=-0.234, p$ $<.01)$. 그리고 교사관계가 높을수록 증가집단에 비해 저수준 집단에 속할 가능성이 더 높았다. 부모요인에서 부모감독의 수준이 높을수록 고수준 집단보다 저수준 집단에 포함될 가능 성이 더 높았으나 $(b=-0.159, p<.05)$, 학대경험이 높을수록 저 수준 집단 보다는 고수준 집단과 급격한 증가집단에 속할 가 능성이 더 높았다 $(b=0.254, p<.001, b=0.241, p<.001)$. 감소 집단과 저수준 집단을 비교하면 자아탄력성, 또래애착 수준이 높을수록 저수준 집단에 속할 가능성이 높았으며 $(b=-0.023, p$ $<.05, b=-0.043, p<.05, b=-1.206, p<.001)$ 교우관계 수준이 높을수록 $(b=0.032, p<.05)$ 감소집단에 속할 가능성이 높았 고, 그 외의 예측변인은 유의하지 않았다. 
Table 4

Results of Multinomial Logistic Regression Analysis

\begin{tabular}{|c|c|c|c|c|c|c|}
\hline & \multicolumn{6}{|c|}{ Reference group: Low group } \\
\hline & \multicolumn{2}{|c|}{ Increasing group } & \multicolumn{2}{|c|}{ High group } & \multicolumn{2}{|c|}{ Decreasing group } \\
\hline & Estimate & S.E. & Estimate & S.E. & Estimate & S.E. \\
\hline \multicolumn{7}{|l|}{ Child Individual predictors } \\
\hline Gender & -0.444 & 0.254 & $-1.206^{* * *}$ & 0.269 & -0.152 & 0.140 \\
\hline Self-esteem & $-0.180^{* * *}$ & 0.033 & $-0.211^{* * *}$ & 0.037 & -0.006 & 0.018 \\
\hline Ego-resilience & $-0.057^{* *}$ & 0.019 & $-0.082^{* * *}$ & 0.022 & $-0.023^{*}$ & 0.012 \\
\hline \multicolumn{7}{|l|}{ Peer and school predictors } \\
\hline Peer attachment & $-0.081^{* *}$ & 0.031 & $-0.084^{*}$ & 0.034 & $-0.043^{*}$ & 0.018 \\
\hline Peer relationship & $-0.177^{* *}$ & 0.065 & $-0.234^{* *}$ & 0.078 & $0.032^{*}$ & 0.040 \\
\hline Teacher-child relationship & $-0.108^{*}$ & 0.047 & -0.041 & 0.050 & -0.044 & 0.029 \\
\hline \multicolumn{7}{|l|}{ Parent predictors } \\
\hline Parental monitering & $-0.168^{*}$ & 0.083 & $-0.159^{*}$ & 0.081 & -0.022 & 0.054 \\
\hline Warmth & -0.081 & 0.067 & -0.087 & 0.068 & -0.034 & 0.045 \\
\hline Abuse & $0.241^{* * *}$ & 0.052 & $0.254^{* * *}$ & 0.052 & 0.043 & 0.033 \\
\hline
\end{tabular}

Note. Gender was included as a dummy variable; girl = 0; boy = 1; S.E. = Standard Error.

${ }^{*} p<.05 .{ }^{* *} p<.01 .{ }^{* * *} p<.001$.

\section{Discussion}

학령기 아동의 내재화 문제에 대해 잠재계층을 분류하고, 성별, 자아존중감, 자아탄력성의 개인요인, 또래애착, 교우관계, 교사 관계의 또래 및 학교요인, 부모감독, 애정, 학대의 부모요인은 잠재계층 별 내재화 문제와 어떠한 관계가 있는지를 알아보고 자 하였다. 연구결과를 선행연구 결과와 관련지어 논의하였다.

첫째, 내재화 문제에 대한 잠재프로파일분석 결과 4 개 잠재 계층으로 구분되었다. 이 4 가지 유형은 내재화 문제의 평균이 가장 낮은 저수준형, 초등학교 2, 3학년보다는 4학년과 6학년 에서 높아지는 증가형, 초등학교 2, 3학년보다는 4학년과 6학 년에서 감소하는 감소형, 그리고 내재화 문제의 평균이 전반적 으로 높은 고수준형으로 분류될 수 있는 것으로 나타났다. 이 러한 결과는 종단자료를 분석하여 3 세에서 15 세 아동과 청소 년(Davis et al., 2015; Sterba et al., 2007)의 내재화 문제에 대한 발달궤적은 3 개에서 6 개의 하위집단으로, 교사평가에 의한 초 등학생의 내재화 및 외현화 문제행동에 대한 잠재계층은 4 개 로 분류된(Gang et al., 2012) 연구결과와 관련지을 수 있다. 이 는 대상자와 측정한 변수, 그리고 측정도구 등의 차이가 있음 에도 불구하고 아동의 내재화 문제의 증가, 감소, 혹은 유지 를 반영하는 이질적인 잠재집단으로 구분될 수 있다는 것을 나타낸다. 성별의 경우 여학생일수록 저수준 집단 보다 고수 준 집단에 포함될 가능성이 높은 것으로 나타난 결과는 초등 학교 4학년에서 중학교 2, 3학년의 시기 동안 여학생이 남학생
에 비해 내재화 문제의 초기치가 높고 변화율도 더 많이 증가 하는 것으로 밝힌 결과(Jwa \& Byeon, 2010; Kang, 2014)와 맥락 을 같이한다. 본 연구결과에서 고수준 집단(8.3\%)과, 증가집단 (15.94\%)에 속하는 아동은 초등학교 4학년과 초등학교 6학년 에서 내재화 문제의 평균이 증가하는 것으로 나타났는데, 초 등학교 4학년에서 6학년 까지 아동의 내재화 문제가 증가하는 것으로 보고한 연구결과(J.-R. Lee, 2008)와 관련된다. 이러한 결과는 사춘기 전기와 초기 청소년기에 신체적, 인지적 변화가 일어나는 시기로 인해 심리내적 조절이 어려워지기 쉽고, 초등 학교에서 중학생으로 환경의 변화가 예상됨에 따라 학업적 성 취에 대한 요구와 기대로 인한 스트레스 등 심리적 부담감으로 내재화 문제 및 심리내적 증상이 증가하는 것으로 볼 수 있다. 내재화 문제는 공격적 행동과 달리 표면적으로 잘 드러나지 않 는 특징이 있어 내재화 문제가 증가할 경우 초기 청소년기 이 후의 정신건강에 작용할 가능성을 있다는 것을 시사한다. 따라 서 사춘기 전기 이후 아동의 정신건강에 대한 평가와 심리검사 를 토대로 내재화 문제의 수준을 완화를 하고 심리사회적 적응 을 촉진하는 중재와 개입 노력이 이루어질 필요가 있다.

둘째, 개인 요인으로 자아존중감, 자아탄력성이 높을수록, 또래 및 학교요인에서 또래애착, 또래관계, 교사관계의 수준 이 높을수록 내재화 문제가 고수준 집단보다는 저수준 집단에 포함될 가능성이 더 높은 것으로 나타났다. 이러한 결과는 높 은 수준의 내재화 문제는 낮은 자아존중감과 관계가 있는 것 으로 밝힌 연구결과(Kim \& Cicchetti, 2004; Song \& Shin, 2014) 
와 관련지을 수 있다. 초등학교 5, 6학년의 내재화 문제는 자아 탄력성과 관계가 있으며(Cho \& Lee, 2007), 높은 수준의 또래 애착과 또래관계는 우울 등 내재화 문제를 예측하고(Bukowski et al., 2010; Duchene \& Ratelle, 2014; Jang \& Chung, 2019), 선 생님과의 애착 및 학교적응은 내재화 문제 수준이 낮은 것으로 나타난 결과(Koo, 2004)와 관련된다. 앞서 논의한 또래애착, 또 래관계, 자아존중감 및 자아탄력성에 관한 본 연구결과를 통 해 학령기 아동은 학년이 높아질수록 또래관계의 비중이 커지 면서 또래로 부터의 수용 혹은 거부는 아동의 자신에 대한 가 치감 즉 자아존중감 형성에 중요한 예측요인이라는 점을 고려 할 필요가 있다. 다시 말해, 또래관계가 좋은 아동은 친구관계 를 통해 자기 가치감을 형성하게 되어 자아존중감이 향상될 수 있으며, 학교 내에서 친구관계에 어려움을 겪거나 갈등의 경험 은 또래애착과 유능감이 부적절한 것으로 지각하여 자아존중 감의 저하로 부정적인 자아개념이 형성되어 내재화 문제가 발 생할 가능성이 있을 것으로 사료된다. 또, 자아탄력성은 아동 이 지각하는 대인관계에서의 유능감과 관련된 개인의 독특한 특성을 포함하는 개념으로(Block \& Kremen, 1996), 환경적 어 려움에 처했을 때뿐만 아니라 일반적 상황 가운데서도 타인에 게 긍정적인 반응을 유도하여 스트레스를 덜 경험하게 하여 내 재화 문제의 야기를 억제하는 것으로 생각해볼 수 있다.

넷째, 부모의 감독 수준이 높을수록 내재화 문제 수준이 고 수준 집단보다는 저수준 집단에 속할 가능성이 높고, 학대적 양육행동의 수준이 높을수록 내재화 문제 수준이 저수준 집단 보다는 고수준 집단에 속할 가능성이 높게 나타난 결과는 초 등학교 4학년 대상으로 부모의 지도감독이 잘 이루어질수록 내재화 문제 수준은 낮았고, 부모의 학대 혹은 처벌적 양육행 동은 높은 수준의 내재화 문제를 예측하는 것으로 밝힌 결과 와 일치한다(Davis et al., 2015; Jwa, 2017; Keily et al., 2003). 한 편, 본 연구결과 중 부모의 애정적 양육행동은 도출된 4 개 잠 재계층의 내재화 문제를 예측하지 않는 것으로 나타났다. 이러 한 결과는 중학생의 내재화와 외현화 문제에 대해 부모의 심리 적 통제의 주 효과가 있었지만, 애정적 양육의 주 효과는 유의 하지 않은 것으로 나타나 부모가 애정적 양육을 하는 경우에도 많은 심리적 통제가 수반되면 내재화 및 외현화 문제행동의 수 준이 높아지는 것으로 나타난 Nam 등(2014)의 연구결과와 부 분적으로 관련이 있다. 다시 말해, 부모의 경우 학령기 아동의 자녀가 학년이 높아지면서 중학교 진학, 초기 청소년기로의 전 이 시기에 주어지는 발달과제에 대처하도록 돕기 위한 과정에 서 보여주는 더 많은 애정적 관심이 아동에게는 과잉기대와 보 호, 심리적 통제나 간섭으로 지각될 수 있다는 점, 학령기 아동
의 경우 후기 아동기에서 초기 청소년기로 접어들면서 부모로 부터의 심리적 분리와 독립, 자율성의 추구에 대한 욕구가 높 아지는 것이 반영된 것으로 유추해볼 수 있다.

이상의 논의를 바탕으로 시사점과 함의를 제시하면 다음과 같다. 먼저, 아동의 발달뿐만 아니라 내재화 문제의 야기는 다 중의 요인 및 자원의 상호작용에 의한 산물이라고 할 수 있다. 이는 아동의 발달 과정에서 개인내적 요인과 아동을 둘러싼 환 경적 요인이 시간 경과에 따른 상호교류적인 관련성을 제시한 다. 아동은 역동적이고 빠르게 변화하는 실체로 서로 다른 시 간과 상황에서의 그들의 행동과 발달적 결과를 어떻게 규정하 느냐에 따라 매우 다른 정보를 제공할 수 있다는 점에서 내재 화 문제 및 부적응적 행동에 대한 개입에 앞서 다중체계적인 사정과 평가가 이루어져야 할 필요가 있을 것이다. 다음, 부모 와 또래는 후기 아동기에서 청소년기 동안 사회적 지지의 중요 한 제공자로, 내재화 문제의 발달은 아동이 낮은 수준의 긍정 적 양육을 경험할 때 사회적 지지를 위해 또래관계로 대체하려 는 행동들이 나타날 수 있다. 긍정적 양육은 높은 또래관계 수 준과 함께 내재화 증상을 경험할 가능성을 감소하고, 부모의 지지라는 자원의 부족과 빈약함은 또래관계의 어려움을 야기 하여 내재화 문제를 경험할 가능성이 더 높아질 수 있다는 것 이다. 이를 위해 아동들이 촉진적인 또래관계의 형성과 유지에 필요한 공감적 경청과 반응하기 등으로 적절하게 아동 자신을 노출하는 것을 배울 수 있는 대인관계 지향적 사회적 기술훈련 등의 프로그램, 또래 간 체험활동의 적극적인 기회 제공을 통 해 사회적 유능감을 촉진할 수 있을 것이다. 또, 학령기 아동의 내재화 문제를 예방하기 위해 부모상담 및 교육의 다양한 전략 을 통한 중재가 우선적인 대안될 수 있을 것이다.

본 연구를 통해볼 때, 초등학교 저학년과 고학년에 해당하 는 학령기 아동의 내재화 문제는 잠재계층을 분류하여 유형화 함으로써 아동의 연령에 따라 증가 혹은 감소 등의 여러 유형 이 있는 것으로 파악되었다. 그리고 성별, 자아존중감, 자아탄 력성의 개인적 특성, 학령기 아동에게 중요한 환경적 맥락을 고려한 또래, 교사의 또래 및 학교요인, 부모요인은 잠재계층 별 내재화 문제를 예측하는 것으로 확인되었었다. 이들 예측 요인은 아동의 내재화 문제에 보호 혹은 위험요인으로 작용할 수 있다는 점을 도출함으로써 아동의 심리사회적 적응을 돕고 내재화 문제의 유발을 예방하기 위한 개입의 구체적인 자료를 제공한다는 점에 의의가 있다. 본 연구가 가진 몇 가지 제한점 및 후속 연구를 위한 제언을 하고자 한다. 첫째, 본 연구에서 사 용한 한국아동·청소년패널조사 자료는 1학년과 5 학년 아동은 포함되는 않은 불연속적인 4 개년 자료에 대해 잠재계층분석을 
적용한 결과이기 때문에 학령기 전체 연령의 아동에게 일반화 하기에는 어렵다는 제약이 따른다. 학령기 아동의 내재화 문제 는 연령에 따른 변화, 지속 기간, 심각성 정도에 있어서 모든 아 동들이 동일한 것이 아니라 다양한 개인차가 존재할 수 있다. 이러한 측면이 포함된 종단적 변화궤적을 반복 측정에 의해 주 어진 관찰변수의 초기값과 시간경과에 따른 변화율로 잠재집 단을 분류하는 성장혼합모형(Jung \& Wickrama, 2008)을 적용 할 경우, 내재화 문제에 대한 잠재집단의 유형은 다르게 나타 날 수 있으므로 전 학년의 학령기 아동을 대상으로 분석해볼 필요가 있다. 둘째, 본 연구에서는 아동의 내재화 문제만을 다 루고 외현화 문제에 대해서는 살펴보지 못한 제한점이 있다. 유아기와 아동기 및 청소년기의 심리적 부적응이나 문제행동 은 임상적 증상과 특징에 따라 내재화와 외현화 문제로 각각 분류되고 있지만 한편 이들 간에 밀접한 관련성이 있어 공동발 생(co-occurrence)에 주의를 기울여야 한다는 주장이 제기됨에 따라(Choi, 2010; Lilienfeld, 2003) 추후 연구에서 학령기 아동기 의 내재화 및 외현화 문제의 공동발생에 대한 변화양상을 잠재 집단으로 분류하여 청소년기와 어떠한 차이가 있는지를 확인 함으로써 아동과 청소년기의 부적응적 문제행동의 발달과 변 화 과정을 보다 구체적으로 파악해볼 수 있을 것이다.

\section{Acknowledgements}

This work was supported by the Ministry of Education of the Republic of Korea and The National Research Foundation of Korea (NRF-2019S1A5B5A07092599).

\section{Conflict of Interest}

No potential conflict of interest relevant to this article was reported.

\section{References}

\section{In English}

Block, J., \& Kremen, A. M. (1996). IQ and ego-resiliency: Conceptual and empirical and separateness. Journal of Personality and Social Psychology, 70(2), 349-361. doi:10.1037/00223514.70.2.349
Bolger, K. E., Patterson, C., J., \& Kupersmidt, J. B. (1998). Peer relationships and self-esteem among children who have been maltreated. Child Development, 69(4), 1171-1197. doi:10.1111/j.1467-8624.1998.tb06166.x

Bronfenbrenner, U., \& Morris, P. A. (2006). The bioecological model of human development. In R. M. Lerner (Ed.), Handbook of child psychology: Theoretical models of human development (6th ed., Vol. 1, pp. 793-828). Hoboken, NJ: Wiley.

Bub, K., McCaterney, K., \& Willett, J. B. (2007). Behavior problems trajectories and first-grade cognitive ability and achievement skills: A latent growth curve analysis. Journal of Educational Psychology, 99, 653-670. doi:10.1037/00220663.99.3.653

Bukowski, W. M., Laursen, B., \& Hoza, B. (2010). The snowball effect: Friendship moderates escalations in depressed affect among avoidant and excluded children. Development and Psychology, 22(4), 749-757. doi:10.1017/S095457941000043X

Davis, S., Votruba-Drzel, E., \& Silk, J. S. (2015). Trajectories of internalizing symptoms from early childhood to adolescence: Associations with temperament and parenting. Social Development, 24(3), 501-520. doi:10.1111/sode.12105

Duchene, S., \& Ratelle, C. F. (2014). Attachment security to mothers and fathers and the developmental trajectories of depressive symptoms in adolescence: Which parenet for which trajectory? Journal of Youth Adolescence, 43, 641-654. doi:10.1007/ s10964-013-0029-z

Ferdinard, R. F., de Nijs, P. F. A., van Lier, P., \& Verhulst, F. C. (2005). Latent class analysis of anxiety and depressive symptoms in referred adolescents. Journal of Affective Disorder, 88(3), 299306. doi:10.1016/j.jad.2005.08.004

Herman, K. C., Bi, Y., Borden, L. A., \& Reinke, W. M. (2012). Latent classes of psychiatric symptoms among chinese children living in poverty. Journal of Child and Family Studies, 21, 391-402. doi:10.1007/s10826-011-9490-z

Hoglund, W. L. G., \& Chisholm, C. A. (2014). Reciprocating risks of peer problems and aggression for children's internalizing problems. Developmental Psychology, 50(2), 586-599. doi:10.1037/a0033617

Jung, T., \& Wickrama, K. S. A. (2008). An introduction to latent class growth analysis and growth mixture modeling. Social and Personality Psychology Compass, 2(1), 302-317. doi:10.1111/ j.1751-9004.2007.00054.x

Keily, M. K., Bates, J. E., Dodge, K. A., \& Pettit, G. S. (2000). A cross-domain growth analysis: Externalizing and internalizing behaviors during 8 years of childhood. Journal of Abnormal Child Psychology, 28(2), 161-179. doi:10.1023/ a:1005122814723

Keily, M. K., Lofthouse, N., Bates, J. E., Dodge, K. A., \& Pettit, G. S. (2003). Differential risks of covarying and pure components in mother and teacher reports of externalizing 
and internalizing behavior across ages 5 to 14 . Journal of Abnormal Child Psychology, 31(3), 267-283. doi:10.1023/ a: 1023277413027

Kim, J., \& Cicchetti, D. (2004). A longitudinal study of child maltreatment, mother-child relationship quality and maladjustment: The role of self-esteem and social competence. Journal of Abnormal child Psychology, 32(4), 341-354.

Lee, E. J., \& Stone, S. L. (2012). Co-occurring internalizing and externalizing behavioral problems: The mediating effect of the negative self-concept. Journal of Youth and Adolescence, 41, 717-731. doi:10.1007/s10964-011-9700-4

Leve, L. D., Kim, H. K., \& Pears, K. C. (2005). Childhood temperament and family environment as predictors of internalizing and externalizing trajectories from ages 5 to 17. Journal of Abnormal Child Psychology, 33(5), 505-520. doi:10.1007/s10802-005-6734-7

Lilienfeld, S. O. (2003). Comorbidity between and within childhood externalizing and internalizing disorders: Reflections and directions. Journal of Abnormal Child Psychology, 31(3), 285291.

Mash, E. J., \& Barkley, R. A. (2014). Child psychopathology (3rd ed.). New York: The Guildford Press.

Millings, A., Buck, R., Montgomery A., Spears, M., \& Stallard, P. (2012). School connectedness, peer attachment, and self-esteem as predictors of adolescent depression. Journal of Adolescents, 35, 1061-1067. doi:10.1016/jadolescence.2012.02.015

Mplus (Version 7.4). [Computer software]. Los Angeles, CA: Muthén \& Muthén.

O'Connor, E. E., Dearing, E., \& Collins, B. A. (2011). Teacherchild relationship and behavior problem trajectories in elementary school. American Educational Research Journal, 48(1), 120-162. doi.10.3102/0002831210365008

Shonk, S. M., \& Cicchetti, D. (2001). Maltreatment, competency deficits, and risk for academic and behavioral maladjustment. Developmental Psychology, 37(1), 3-17. doi:10.1037//00121649.37.1.3

Sterba, S. K., Prinstein, M J., \& Cox, M. J. (2007). Trajectories of internalizing problems across childhood: Heterogeneity, external validity, and differences. Development and Psychopathology, 19(2), 345-366. doi:10.1017/S0954579407070174

Tambelli, R., Laghi, F., Odorisio, F., \& Notari, V. (2012). Attachment relationships and internalizing and externalizing problems among Italian adolescents. Children and Youth Services Review, 34(8), 1465-1471. doi:10.1016/j. childyouth.2012.04.004

Wang, C., Williams, K. E., Shahaeian, A., \& Harrison, L. J. (2018). Early predictors of escalating internalizing problems across middle childhood. School Psychology Quarterly, 33(2), 200212. doi.10.1037/spq0000218

\section{In Korean}

Cho, G.-Y., \& Lee, E.-H. (2007). Early adolescent's ego-resiliency: Mediational links between parenting behaviors, family strength, and behavior problems. Studies on Korean Youth, 18(1), 79-106.

Choi, J.-A. (2010). The reciprocal causation between delinquency and depression during early adolescence: Testing autoregressive cross-lagged effects. Studies on Korean Youth, 21(4), 143-169.

Gang, J.-H., Kim, J.-C., Yun, K.-H., \& Lim, E.-M. (2012). The effects of multicultural family, gender, parents, and individual capacity on elementary students' internalizingexternalizing latent class. The Journal of Educational Research, 10(4). 201-224

Han, S. A., \& Moon, S. B. (2011). A structural analysis on schoolaged children's school adjustment and its related variables. Journal of Future Early Childhood Education, 18(3), 355376.

Jang, E., \& Chung, H. (2019). The longitudinal mediating effects of school connectedness on the links between adolescents' perceived peer attachment and depression. Studies on Korean Youth, 30(1), 313-340. doi:10.14816/sky.2019.30.1.313

Jo, M.-J., \& Kim, M.-J. (2014). An study of gender differences on influencing factors of internalizing/externalizing problem behaviors of adolescents: Focusing on marital conflict and attachment of parents. Journal of Critical Social Welfare, 45, 267-303.

Jwa, H. (2010). Risk factors and protective factors on internalizing problem of adolescents. Korean Journal of Youth Studies, 17(10), 105-133.

Jwa, H. (2016). A meta-analysis on relationship between adolescents' internalizing problem and protective factors. Journal of School Social Work, 36, 97-127.

Jwa, H. (2017). A meta-analysis of adolescents' internalizing problem and risk factors. Forum For Youth Culture, 49, 85119. doi:10.17854/ffyc.2017.01.49.85

Jwa, H., \& Byeon, K. Y. (2010). The developmental trajectories and factors associated with internalizing problem from late childhood to early adolescence. Journal of School Social Work, 19, 113-140.

Kang, J. H. (2014). Developmental trajectories of internalizing and externalizing problems in late-childhood: The effect of children's gender, perceived academic achievements, parents' behaviors, and peer relations. The Korean Journal of Elementary Counseling, 13(1), 155-173.

Koo, J. G. (2004). The relationship between school related psychosocial characteristics and mental health. Korean Journal of Youth Studies, 11(2), 217-239.

Lee, E.-J. (2010). Longitudinal co-developmental of internalizing and externalizing problem behaviors: A cross-domain latent 
growth curve modeling approach. Studies on Korean Youth, 21(4), 171-200.

Lee, H.-E., \& Moon, S.-B. (2011). A structural analysis on schoolaged children's school adjustment and its related variables. Journal of Korean Home Management Association, 29(4), 161-174.

Lee, J.-R. (2008). Trajectories of change in internalizing and externalizing problems in elementary school students: Latent growth curve modeling. Journal of Korean Council for Children \& Rights, 12(4), 503-523.

Lee, S. (2008). Influence of protective and risk factors on delinquent behavior trajectories. Korean Journal of Social Welfare Studies, 39, 315-342. doi:10.16999/kasws.2008..39.315

Nam, J.-M., Sung, H.-R., \& Gwon, S.-Y. (2014). Effects of psychological control and affective parenting on internalized and externalized behaviors in junior middle schoolers. The Korean Journal of Developmental Psychology, 27(3), 147-167.

National Youth Policy Institute. (2016). Korean children and youth panel survey [Data file and code book]. Retrieved from
NYPI website: https://www.nypi.re.kr/archive

No, U., \& Hong, S. (2010). Identifying latent classes in early adolescents' emotional depression changes and testing relationship as determinants of the classes. The Korean Journal of Educational Methodology Studies, 22(2), 91-110.

Song, H. S., \& Shin, H. S. (2014). A predictive model of behavioral problems in elementary school children. Child Health Nursing Research, 20(1), 1-10. doi:10.4094/chnr.2014.20.1.1

Young Ae Lee http://orcid.org/0000-0002-4285-7470

Received February 29, 2020

Revision received April 24, 2020

Accepted May 29, 2020 